\title{
Effectiveness of MRI for the Assessment of Mesorectal Fascia Involvement in Patients with Rectal Cancer: A Systematic Review and Meta-Analysis
}

\author{
Haiting Xie ${ }^{a} \quad X_{\text {Xn Zhou }}^{a} \quad Z_{\text {Zize Zhuo }}^{c}$ Shunan Che ${ }^{b} \quad$ Lingduo Xie $^{a} \quad$ Wei Fu ${ }^{a}$ \\ Departments of a General Surgery and ${ }^{\mathrm{b}}$ Radiology, Peking University Third Hospital, and ' School of Public Health, \\ Peking University, Beijing, China
}

\section{Key Words}

Rectal cancer · Preoperative staging · Mesorectal fascia ·

$\mathrm{MRI} \cdot$ Meta-analysis

\begin{abstract}
Aims: Defining the most appropriate definition of mesorectal fascia involvement (MRF+) by reviewing literature and using new inclusion criteria to re-evaluate the effectiveness of MRI in the assessment of MRF+ for rectal cancer. Methods: PubMed, Medline, Embase, and the Cochrane Library databases were electronically searched from 1999 to 2012. The bivariate random effects model was used to estimate the pooled outcomes of each subgroup. The definition of MRF+ in MRI and the influence of neoadjuvant chemoradiotherapy (neo-ChRT) were especially discussed. Results: Fourteen studies involving 1,600 patients were included. Different definitions of MRF+ $(\leq 1, \leq 2$ and $\leq 5 \mathrm{~mm})$ in MRI exhibited different pooled sensitivity (76, 79 and 92\%), specificity (88, 66 and 48\%) and diagnostic odds ratio (DOR) (22.4, 6.6 and 16.0). The definition of MRF+ at $\leq 1 \mathrm{~mm}$ showed the highest DOR. The specificity ( 88 vs. 93\%, $\mathrm{p}=0.026$ ) and DOR (15.5 vs. $39.0, p=0.001$ ) were lower in patients who underwent neoChRT than those who did not while using $\leq 1 \mathrm{~mm}$ as the definition of MRF+. However, the sensitivity showed no signifi-
\end{abstract}

cant difference (67 vs. $74 \%, p=0.129$ ). Conclusions: $M R I$ is valuable for the assessment of MRF. The most appropriate definition of MRF+ in MRI is $\leq 1 \mathrm{~mm}$. The effectiveness is higher in patients who did not undergo neo-ChRT.

(c) 2014 S. Karger AG, Base

\section{Introduction}

Since it was first put forward by Heald et al. [1] in 1982, total mesorectal excision (TME) has been used as the standard procedure to treat mid-low rectal cancers with significant local recurrence rate [2-6]. However, some studies revealed an unfavorable local recurrence rate after standardized TME procedures in a small population of patients. Further studies $[7,8]$ suggested that preoperative mesorectal fascia involvement $(\mathrm{MRF}+)$ is an independent risk factor. MRF is defined as the fine linear structure enveloping the mesorectal compartment harboring the rectum perirectal fat [9], and it is considered to be involved if the distance between the tumor tissue and MRF is $\leq 1 \mathrm{~mm}$ in histopathology [10]. A metaanalysis by Nagtegaal and Quirke [11] showed the patients with preoperative MRF+ had higher local recurrence and distant metastasis rate, as well as reduced life

\section{KARGER}

E-Mail karger@karger.com

www.karger.com/dsu
C 2014 S. Karger AG, Basel

0253-4886/14/0312-0123\$39.50/0
Wei Fu

Department of General Surgery, Peking University Third Hospital

No. 49 North Huayuan Road

Haidian District, Beijing 100191 (China)

E-Mail fuwei0720@ sohu.com 
expectancy. The main approaches to assess MRF are CT and MRI. Since MRI can achieve better contrast resolution, it is more reliable in the assessment of MRF+ [12, 13]. However, the definition of MRF+ in MRI is still controversial. Three previous meta-analyses have already evaluated the effectiveness of MRI in the assessment of $\mathrm{MRF}+$ for rectal cancer [14-16]. But in their studies, patients who underwent neoadjuvant chemoradiotherapy (neo-ChRT) were not studied. It is generally accepted that a second MRI scan is helpful to identify a potentially involved MRF after neo-ChRT in patients with locally advanced rectal cancer [9]. So it is also important and necessary to study patients who underwent neo-ChRT. Besides, a clear definition of MRF+ was not given in their studies. Studies with the definition like 'contiguity of tumor and the mesorectal fascial reflection' were also included (see Appendix 2), which might have influenced the accuracy of outcomes. Based on this, we conducted this meta-analysis to get the most appropriate definition of MRF+ in MRI and to revalue MRI in the assessment of MRF. As far as we know, this is the first meta-analysis to compare the most appropriate definition of MRF+ and to include the influence of neo-ChRT on MRI accuracy in predicting MRF+.

\section{Methods}

Criteria for Study Eligibility

Studies were included if they fulfilled the following criteria: (a) histopathology was used as the golden standard, (b) the definition of MRF+ was $\leq 1 \mathrm{~mm}$ in histopathology, and $\leq 1, \leq 2$ or $5 \mathrm{~mm}$ in MRI, (c) original articles (if data were used in more than one article, only the newest paper was included), and (d) original primary data were available to extract or reconstruct $2 \times 2$ contingency tables. If not, authors were contacted to request this information.

Studies having any of the following features were not eligible for inclusion: (a) non-English articles, (b) animal experiments, and (c) reports only as abstract, review and lecture.

\section{Literature Search and Data Extraction}

A literature search was performed for relevant publications in PubMed, Medline, Embase and Cochrane Central (1.1.199930.6.2012). We retrieved 132 studies in PubMed, 249 in Embase and Medline, and 8 in Cochrane Central (see Appendix 1). Reference lists of these retrieved articles were also searched manually to identify relevant studies and 3 studies were identified. By reading abstracts of all these studies independently by two veteran reviewers, a total of 149 studies that may fit the inclusion criteria were identified.

\section{Assessment of Methodological Quality}

Quality was assessed using the checklist of Quality Assessment of Diagnostic Accuracy Studies (QUADAS), which is recommend- ed by Cochrane Collaboration [17]. Each quality item was scored as 'yes', 'no' or 'unclear'. Two reviewers independently reviewed the studies to evaluate the 11 different quality indexes of each study. In case of disagreement, it was resolved by discussion or consulting with a third reviewer. According to Whiting et al. [18], we did not calculate the summary scores because of its problematic interpretation.

\section{Statistical Analysis}

In this study, bivariate random effects model $[19,20]$ was used to generate the summary estimates of sensitivity, specificity, and diagnostic odds ratio (DOR) through Stata software (Stata SE 12). RevMan 5 (Review Manager software 5.0) was used to draw the summary of receiver-operating characteristic (SROC) curves. In covariate analyses, $t$ test was used and the $\mathrm{p}$ value was calculated. The pooled sensitivity, specificity and DOR were compared in patients who underwent neo-ChRT (MRI after neo-ChRT vs. histopathology) and who did not (baseline MRI vs. histopathology) when analyzing the influence of neo-ChRT.

\section{Investigations of Heterogeneity}

Heterogeneity could be caused by the following factors: (a) whether patients underwent neo-ChRT, (b) definition of MRF+ in MRI, (c) tumor location, (d) tumor stage, (e) QUADAS items 1, 3 and 7, (f) types of operation, (g) patients' age and sex, (h) tumor differentiation, (i) different parameters of MRI, (j) different time intervals between MRI and surgery, and $(\mathrm{k})$ treatments by different surgeons, pathologists and radiologists.

\section{Results}

\section{Literature Search and Selection of Studies}

The literature search identified 389 references and a total of 149 full studies were retrieved, of which 14 were considered relevant for this meta-analysis (fig. 1) [21-34].

\section{Study Characteristics}

A total of 14 studies and 1,600 patients were included in this study (table 1), including 8 prospective, 4 retrospective and 2 undefined studies. Among the 14 studies, 2 did not have neo-ChRT and 12 did. All 14 studies used $\leq 1 \mathrm{~mm}$ as the definition of MRF+, but 3 of them $[26,32$, 34] also used other definitions ( $\leq 2$ and $\leq 5 \mathrm{~mm}$ ). A total of 10 studies and 1,286 patients (636 of whom had neoChRT) were included when discussing the influence of neo-ChRT (table 2). Four studies [29, 32-34] were excluded because they were not available to extract or reconstruct $2 \times 2$ contingency tables of patients who had neo-ChRT and those who did not separately. From table 2 we can see 7 of the 10 included studies had neoChRT and they all had second MRI and were compared with the final histopathology. 
Fig. 1. Flowchart of search results.

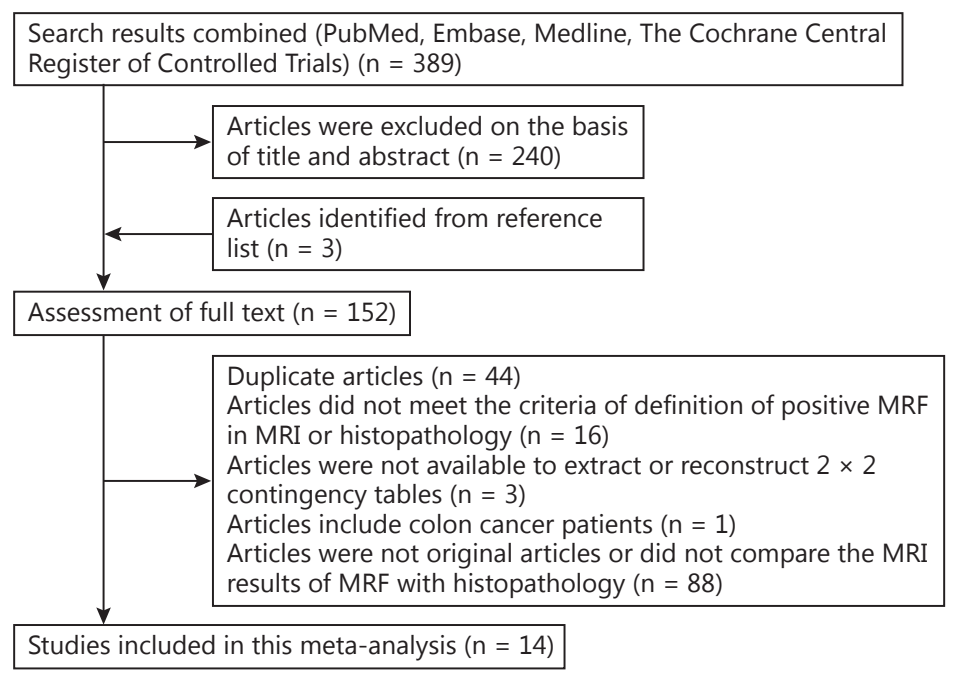

Table 1. Characteristics of the included studies

\begin{tabular}{|c|c|c|c|c|c|c|c|c|c|c|c|c|c|c|c|c|}
\hline \multirow[t]{2}{*}{ Study } & \multirow[t]{2}{*}{ Year } & \multirow[t]{2}{*}{ Design } & \multirow[t]{2}{*}{$\mathrm{n}$} & \multirow[t]{2}{*}{ Sen } & \multirow[t]{2}{*}{ Spe } & \multirow[t]{2}{*}{$\begin{array}{l}\text { Tesla } \\
\text { of MRI }\end{array}$} & \multirow{2}{*}{$\begin{array}{l}\text { Using } \\
\text { DWI } \\
\text { of MRI }\end{array}$} & \multirow{2}{*}{$\begin{array}{l}\text { Used meta- } \\
\text { static lymph } \\
\text { node? }\end{array}$} & \multirow{2}{*}{$\begin{array}{l}\text { Neo- } \\
\text { ChRT: } \\
\text { NOT }^{\mathrm{b}}\end{array}$} & \multirow[t]{2}{*}{$1 \mathrm{~mm}^{\mathrm{c}}$} & \multirow[t]{2}{*}{$\begin{array}{l}2 \text { or } \\
5 \mathrm{~mm}^{\mathrm{c}}\end{array}$} & \multicolumn{2}{|c|}{ T stage } & \multicolumn{3}{|c|}{$\begin{array}{l}\text { Distance from the } \\
\text { anal verge, } \mathrm{cm}\end{array}$} \\
\hline & & & & & & & & & & & & $\mathrm{T} 0-2$ & $\mathrm{~T} 3-4$ & $0-5$ & $5-10$ & $10-15$ \\
\hline Giusti [21] & 2012 & retrospective & 96 & 1.000 & 0.850 & 1.5 & no & $?^{\mathrm{d}}$ & $48: 48$ & yes & no & 46 & 50 & $?$ & $?$ & $?$ \\
\hline Nougaret [22] & 2012 & retrospective & 58 & 0.667 & 0.796 & 1.5 & yes & $?$ & $58: 0$ & yes & no & 34 & 24 & 42 & 16 & 0 \\
\hline Pomerri [23] & 2011 & retrospective & 68 & 0.500 & 0.900 & 1.0 & no & yes & $68: 0$ & yes & no & $?$ & $?$ & $?$ & $?$ & $?$ \\
\hline Taylor [24] & 2011 & prospective & 374 & 0.642 & 0.907 & $?$ & no & $?$ & $216: 158$ & yes & no & $?$ & $?$ & 113 & 261 & \\
\hline Kim [25] & 2009 & prospective & 66 & 0.942 & 0.571 & 1.5 & no & $?$ & $0: 66$ & yes & no & 22 & 44 & 10 & 56 & $?$ \\
\hline Tytherleigh [26] & 2008 & prospective & 46 & 0.286 & 0.795 & 1.0 & no & yes & $46: 0$ & yes & yes & $?$ & $?$ & $?$ & $?$ & $?$ \\
\hline Kulkarni [27] & 2008 & prospective & 80 & 0.538 & 0.866 & 1.0 & no & no & $80: 0$ & yes & no & 36 & 44 & $?$ & $?$ & $?$ \\
\hline Strassburg [28] & 2007 & retrospective & 68 & 1.000 & 1.000 & 1.0 or 1.5 & no & yes & $23: 45$ & yes & no & 22 & 46 & 17 & $31^{\mathrm{f}}$ & $20^{\mathrm{f}}$ \\
\hline Videhult [29] & 2007 & prospective & 91 & 0.800 & 0.864 & 1.0 or 1.5 & no & $?$ & $?$ & yes & no & 20 & 71 & 18 & $?$ & $?$ \\
\hline \multicolumn{17}{|l|}{ MERCURY Study } \\
\hline Group [30] & 2006 & prospective & 408 & 0.593 & 0.924 & $?$ & no & yes & $97: 311$ & yes & no & 136 & 272 & 139 & 145 & 101 \\
\hline Ferri [31] & 2005 & $?$ & 22 & 1.000 & 0.900 & 1.5 & no & $?$ & $0: 22$ & yes & no & $?$ & $?$ & $?$ & $?$ & $?$ \\
\hline Brown [32] & 2003 & prospective & 98 & 0.810 & 0.974 & 1.5 & no & yes & $?$ & yes & yes & 28 & 70 & 13 & 85 & \\
\hline Martling [33] & 2003 & retrospective & 99 & 0.800 & 0.725 & 1.5 & no & yes & $?$ & yes & no & $?$ & $?$ & $?$ & $?$ & $?$ \\
\hline Blomqvist [34] & 1999 & $?$ & 26 & 0.875 & 0.778 & 1.5 & no & $?$ & $24: 2$ & yes & yes & $?$ & $?$ & $?$ & $?$ & $?$ \\
\hline
\end{tabular}

Sen = Sensitivity; Spe $=$ specificity. ${ }^{\text {a }}$ Whether metastatic lymph node was used for measuring the closest distance to the MRF. ${ }^{b} \mathrm{Neo}-\mathrm{ChRT}=\mathrm{The}$ number of patients who had neo-ChRT. NOT $=$ The number of patients who did not have neo-ChRT. ${ }^{c}$ Whether 1,2 or $5 \mathrm{~mm}$ was used as the definition of MRF+ in MRI. ${ }^{\mathrm{d}}$ Character '?' means 'unclear' in this table. ${ }^{\mathrm{e}}$ This study did not subdivide between $5-10$ and $10-15 \mathrm{~cm}$. ${ }^{\mathrm{f}}$ This study divided the group as $0-6,6-12$ and $12-16 \mathrm{~cm}$.

\section{Quality Assessment}

The quality of included studies is summarized in table 3. It shows that the main disagreement is in 3 out of the 11 quality indexes (items 1,3 and 7). In this study, item 1 indicates that studies should include all kinds of rectal cancer including upper, middle, lower and T1-T4 rectal cancers. Only 5 studies met this criterion. Item 3 is defined as follows: if the patient underwent neo-ChRT the surgery should be performed in 5-10 weeks, otherwise the surgery should be performed in 8 weeks after neo-ChRT. Only 6 studies met this criterion. Item 7 indicates that histologists did not know the results of MRI when they were analyzing the specimens. Twelve studies did not describe this practice. 
Table 2. Characteristics of 10 studies included in discussing the influence of neo-ChRT

\begin{tabular}{|c|c|c|c|c|c|c|c|c|c|c|c|c|}
\hline Study & $\mathrm{n}$ & Sen & Spe & $\mathrm{n}$ & Sen & Spe & $\mathrm{n}$ & Sen & Spe & $\begin{array}{l}\text { Second } \\
\text { MRI after } \\
\text { neo-ChRT }\end{array}$ & DWI & $\begin{array}{l}\text { Time of } \\
\text { interval, } \\
\text { days }^{\mathrm{a}}\end{array}$ \\
\hline Giusti [21] & 96 & 1.000 & 0.850 & 48 & 1.000 & 0.667 & 48 & 1.000 & 1.000 & yes & no & $\leq 14$ \\
\hline Nougaret [22] & 58 & 0.667 & 0.796 & 58 & 0.667 & 0.800 & 0 & l & l & yes & yes & $6-14$ \\
\hline Pomerri [23] & 68 & 0.500 & 0.900 & 68 & 0.500 & 0.900 & 0 & l & l & yes & no & $14-21$ \\
\hline Tytherleigh [26] & 46 & 0.286 & 0.795 & 46 & 0.286 & 0.795 & 0 & l & l & yes & no & $\leq 2$ \\
\hline Kulkarni [27] & 80 & 0.538 & 0.866 & 80 & 0.538 & 0.866 & 0 & / & / & yes & no & 21 \\
\hline Strassburg [28] & 68 & 1.000 & 1.000 & 23 & 1 & 1 & 45 & 1 & 1 & yes & no & $?$ \\
\hline \multicolumn{13}{|l|}{ MERCURY } \\
\hline Study Group [30] & 408 & 0.593 & 0.924 & 97 & 0.944 & 0.734 & 311 & 0.417 & 0.978 & yes & no & 30 \\
\hline Ferri [31] & 22 & 1.000 & 0.900 & 0 & I & I & 22 & 1.000 & 0.900 & i & no & I \\
\hline
\end{tabular}

Sen = Sensitivity; Spe = specificity. ${ }^{\text {a }}$ Time of interval between surgery and second MRI after neo-ChRT.

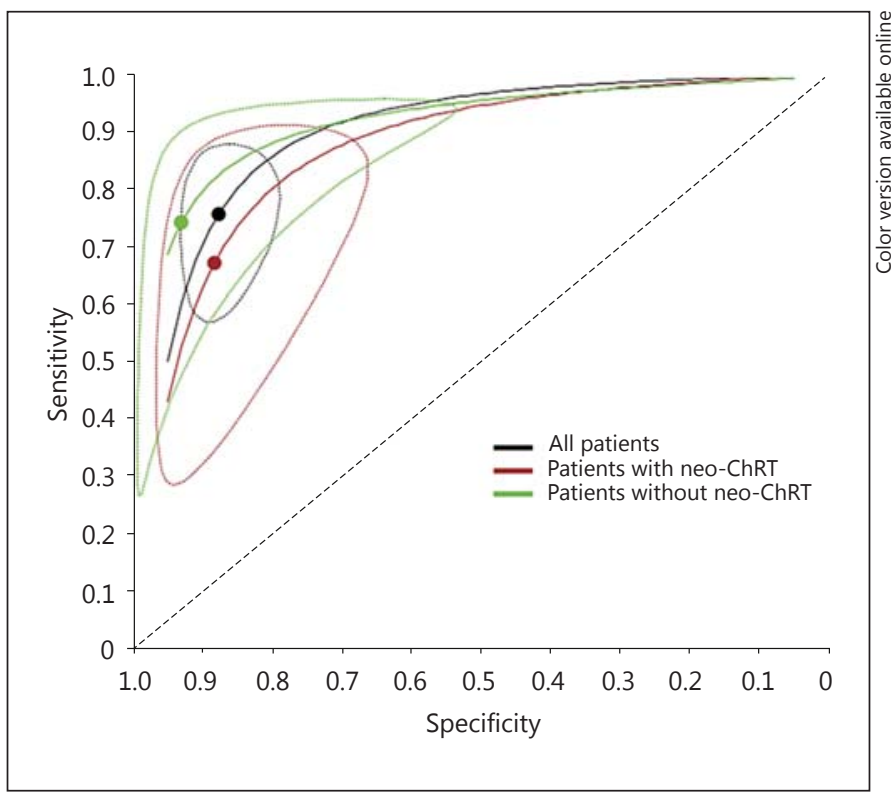

Fig. 2. SROC curve of MRI for assessment of MRF in rectal cancer, with 95\% confidence region (dotted lines) for all subgroups. Each confidence region has a summary point (dots) which represents the most likely values of true summary sensitivity and specificity.

\section{Data Analysis}

From table 4, we can see the different definitions of MRF+ $(\leq 1, \leq 2$ and $\leq 5 \mathrm{~mm})$ in MRI exhibited different pooled sensitivity ( 76,79 and $92 \%$, respectively), specific- ity $(88,66$ and $48 \%$, respectively) and DOR $(22.4,6.6$ and 16.0 , respectively). The definition of MRF+ at $\leq 1 \mathrm{~mm}$ showed the highest DOR. Table 5 shows the details of each outcome and figure 2 shows each SROC curve when using $\leq 1 \mathrm{~mm}$ as the definition of MRF+. Summary estimates of sensitivity, specificity and DOR were produced with $95 \%$ confidence interval (CI).

\section{Covariate Analyses}

Based on the heterogeneity investigations, we performed covariate analysis of items a, b, e, and i. Though items $\mathrm{c}, \mathrm{d}, \mathrm{j}$ and $\mathrm{k}$ also have very important influences on the results, covariate analysis was not performed due to insufficient data.

As shown in table 5 , sensitivity, specificity and DOR of patients who underwent neo-ChRT were 67\% (95\% CI 43-85\%), 88\% (95\% CI 77-95\%) and 15.5 (95\% CI 6.537.0). The specificity and DOR were much lower ( $\mathrm{p}=$ 0.026 and 0.001 ) and the sensitivity showed little difference $(\mathrm{p}=0.1286)$, comparing with the patients who did not undergo neo-ChRT.

The full details of pooled sensitivity, specificity and DOR of the other subgroups are listed in table 5. The sensitivity, specificity and DOR were all much higher ( $\mathrm{p} \leq$ 0.05 ) when MRI was performed on 1.5-tesla (T) instruments compared with 1.0-T instruments. The type of studies (retrospective vs. prospective) had marked influence on the sensitivity ( $p \leq 0.01$ ), but not on the specificity and DOR. 
Table 3. Methodological quality of the included studies

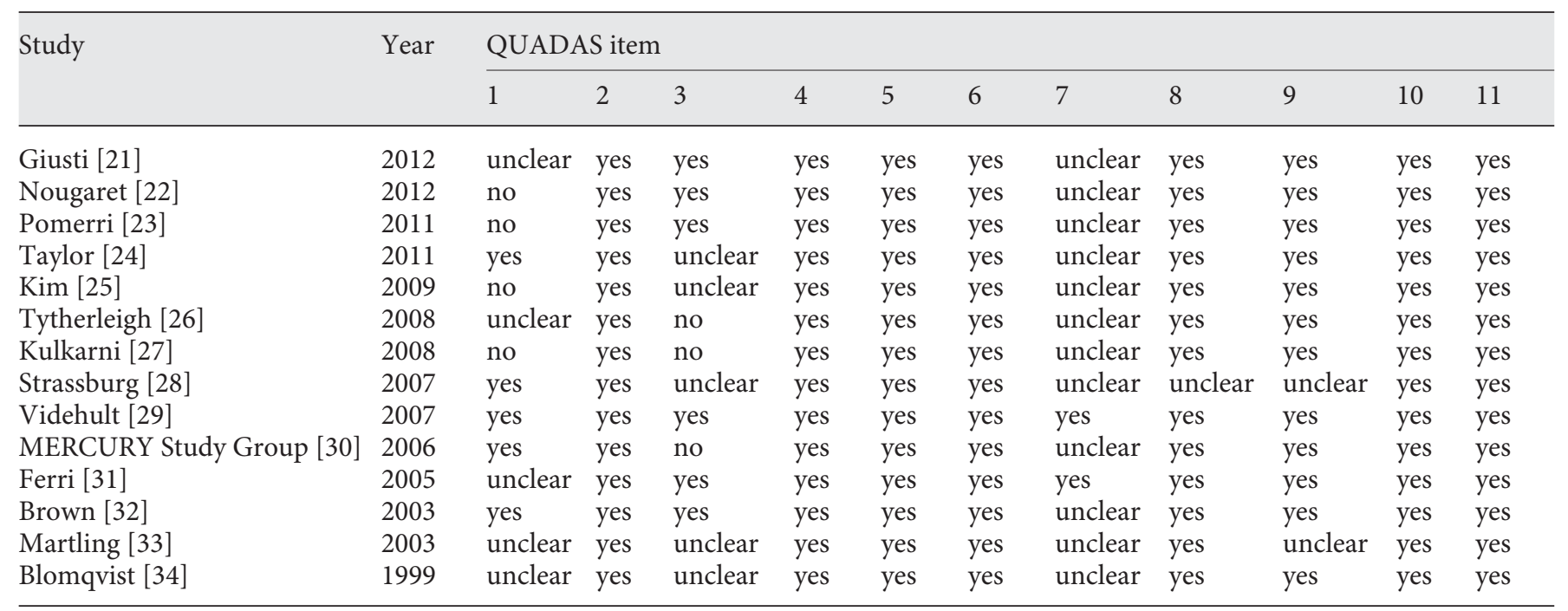

1 = Representative spectrum, in this meta-analysis it means tumors from all levels of rectum (upper, mid, low; T1-T4). 2 = Acceptable reference standard. 3 = Acceptable delay between tests, in this meta-analysis it means time period $\leq 8$ weeks between MRI and surgery ( $\leq 2$ weeks if patient received pre-RCT) [9]. $4=$ Partial verification avoided. $5=$ Differential verification avoided. $6=$ Incorporation avoided. $7=$ Index test results blinded. $8=$ Reference standard results blinded. $9=$ Relevant clinical information. $10=$ Uninterruptable results reported. $11=$ Withdrawals explained.

Table 4. Sensitivity, specificity and DOR for different definitions of MRF+

\begin{tabular}{llll}
\hline Definition & $\begin{array}{l}\text { Sensitivity, \% } \\
(95 \% \mathrm{CI})\end{array}$ & $\begin{array}{l}\text { Specificity, \% } \\
(95 \% \mathrm{CI})\end{array}$ & $\begin{array}{l}\text { DOR } \\
(95 \% \mathrm{CI})\end{array}$ \\
\hline$\leq 1 \mathrm{~mm}$ & $76(63-85)$ & $88(82-92)$ & $22.4(11.4-43.8)$ \\
$\leq 2 \mathrm{~mm}$ & $79(66-88)$ & $66(61-71)$ & $6.6(3.4-12.6)$ \\
$\leq 5 \mathrm{~mm}$ & $92(83-97)$ & $48(43-53)$ & $16.0(1.2-219.2)$ \\
\hline
\end{tabular}

\section{Discussion}

For the definition of MRF+ in histopathology, $\leq 1 \mathrm{~mm}$ was recommended by the National Comprehensive Cancer Network (NCCN) [10], and this study adopted this definition. There is much debate about the definition of MRF+ in MRI. We consider $\leq 1 \mathrm{~mm}$ to be the most appropriate definition in MRI. The reasons are as follows: in the studies of our initial search, there were 4 types of definitions of MRF+ $(\leq 1, \leq 2, \leq 5 \mathrm{~mm}$ and no specific distance) (see Appendix 2) and ' $\leq 1 \mathrm{~mm}$ ' is the most frequently used one. 17 of the articles used ' $\leq 1 \mathrm{~mm}$ ' as the definition, 14 were included in this study and 3 [35-37] were excluded due to lack of data. Previous articles showed the distances of the tumor to MRF revealed by MRI and histology was in good agreement [38-40]. Brown et al. [39] pointed out that specimen fixation or processing had no appreciable effect on the measurement of distance from tumor to MRF. This observation implies the distance of the tumor to MRF measured in MRI and histopathology had little difference. Because the definition of MRF+ in histopathology is $\leq 1 \mathrm{~mm}$ [10], using $\leq 1 \mathrm{~mm}$ as the definition of MRF+ in MRI appears to be the most appropriate. Though Beets-Tan et al. [41] found that a tumor-free MRF of at least $1.0 \mathrm{~mm}$ can be predicted with a high degree of certainty when the measured distance on MRI is at least 5.0 $\mathrm{mm}$, that difference in distance between MRI and histopathology had already been reduced [22] with consistent use of a high-resolution technique and the improved skills of radiologists. Nowadays, Beets-Tan and colleagues [42] also use $\leq 1 \mathrm{~mm}$ for invasion and $\leq 2 \mathrm{~mm}$ which they call high risk. In addition, we found that in the 3 subgroups concerning $\mathrm{MRF}+(\leq 1, \leq 2$ and $\leq 5 \mathrm{~mm})$, ' $\leq 1 \mathrm{~mm}$ ' group exhibited the highest DOR (table 4). Recently, a multicenter study suggests that using the definition of $\leq 1 \mathrm{~mm}$ did not decrease the accuracy of MRI in predicting MRF status compared with the definition of $\leq 2 \mathrm{~mm}$ or even $\leq 5 \mathrm{~mm}$. On the contrary, it would reduce overtreatment that could achieve only minimal gain based on very low 
Table 5. Sensitivity, specificity and DOR for MRF+ $(\leq 1 \mathrm{~mm})$ in different subgroups

\begin{tabular}{llcc}
\hline Subgroups & Sensitivity, \% (95\% CI) & Specificity, \% (95\% CI) & DOR (95\% CI) \\
\hline All studies & $76(63-85)$ & $88(82-92)$ & $22.4(11.4-43.8)$ \\
Exclude two studies $^{\mathrm{a}}$ & $77(67-85)$ & $86(81-90)$ & $21.6(13.3-35.2)$ \\
Exclude Blomqvist et al. $^{\mathrm{b}}$ & $75(62-85)$ & $88(82-92)$ & $22.4(10.9-46.2)$ \\
Studies used 1.5 T $^{\mathrm{c}}$ & $87(78-93)$ & $83(72-91)$ & $35.0(14.5-84.7)$ \\
Studies used lymph node $^{\mathrm{d}}$ & $68(50-82)$ & $93(81-97)$ & $27.2(5.7-129.3)$ \\
\hline Patients have neo-ChRT $^{\mathrm{e}}$ & $67(43-85)$ & $88(77-95)$ & $15.5(6.5-37.0)$ \\
Patients did not have neo-ChRT $^{\mathrm{f}}$ & $74(49-90)$ & $93(79-98)$ & $39.0(18.9-80.5)$ \\
p value $^{\text {Retrospective studies }}$ & 0.129 & 0.026 & 0.001 \\
Prospective studies & $97(20-100)$ & $89(64-98)$ & $288.1(0.7-113,857)$ \\
p value & $72(58-83)$ & $88(82-92)$ & $19.0(10.3-35.0)$ \\
\hline
\end{tabular}

\footnotetext{
a Two studies: only one study [27] has the highest accuracy and the other [25] has the lowest accuracy. ${ }^{\mathrm{b}}$ Blomqvist et al. [34]: MRI scan was performed on the specimen (in vitro) in this study. ${ }^{\mathrm{c}}$ Studies used $1.5 \mathrm{~T}$ : the studies which used 1.5 T of MRI in all patients (7 studies, details in table 1$){ }^{\mathrm{d}}$ Studies used lymph node: studies in which metastatic lymph node was used for measuring the closest distance to the MRF (6 studies, details in table 1). ${ }^{\text {e }}$ Sensitivity, specificity and DOR were calculated by comparing MRI after neo-ChRT with histopathology. ${ }^{\mathrm{f}}$ Sensitivity, specificity and DOR were calculated by comparing baseline MRI with histopathology.
}

local recurrence ( 89 of 216 additional patients would have been treated to prevent seven potential local recurrences when using $\leq 5 \mathrm{~mm}$ as the definition) [24]. For all these discussed reasons, we consider $\leq 1 \mathrm{~mm}$ to be the best definition of MRF+ in MRI.

From table 4, we can see the sensitivity, specificity and DOR are $76 \%, 88 \%$ and 22.4 , respectively, when we adopt $\leq 1 \mathrm{~mm}$ as the definition. It is much lower compared with the results by Al-Sukhni et al. [16] (77\%, 94\% and 56.1, respectively), which is the latest study and also has the largest amount of patients among the three previous meta-analyses [14-16]. The following factors could have caused these differences: first, neo-ChRT is probably the most important factor; second, we only included studies that used a definition of MRF+ at $\leq 1 \mathrm{~mm}$ both in MRI and histopathology, and third, we have included studies that were published after Al-Sukhni's study [21-24].

Al-Sukhni et al. [16] excluded patients who had neoChRT, because they considered neo-ChRT administered after MRI might downstage the tumor so that final histopathology no longer represented an appropriate reference standard for the original MRI. However, we still considered MRI valuable in the assessment of MRF of neoChRT patients for the following reasons: first, when we calculate the influence of neo-ChRT, all studies (table 2) did a second MRI after neo-ChRT and were compared with the final histopathology, thus reducing the differ- ences; second, studies showed that preoperative shortcourse radiotherapy or radiochemotherapy has little influence on MRF+ [11,43,44], and third, not all patients' MRI before neo-ChRT could be gained. In this situation, the MRI after neo-ChRT became the only data we could use.

Table 5 shows that the DOR and specificity were much lower when patients had neo-ChRT, because there was much fibrosis and tumor 'scar', which made it difficult to distinguish from treated tumor [29, 30, 32]. Studies show that MRI using diffusion-weighted imaging (DWI) can increase the accuracy in patients who had neo-ChRT. One of the reasons is that DWI provides information that reflects tissue cellularity and the integrity of cellular membranes and it is sensitive to intratumoral changes induced by chemoradiation therapy, so it is easier to discriminate between fibrosis and residual tumor [45-51]. Park et al. [46] showed that the accuracy improved from 0.4 (0.69 in observer 2) to 0.89 (0.93 in observer 2). In our 14 included studies, only 1 used DWI (table 1), so we did not analyze the influence of using DWI.

Apart from DWI, other instruments of MRI can also influence the estimates of MRI, especially the different magnetic strength (T). Al-Sukhni et al. [16] found 3.0 T MRI had much higher specificity than 1.0 or $1.5 \mathrm{~T}$ on $\mathrm{T}$ staging, but Maas et al. [52] showed no difference between 3 and 1.5 T MRI for the T staging. In our analysis, 
no study used the 3.0 T MRI, but the 1.5 T MRI showed higher sensitivity, specificity and DOR than 1.0 T MRI (table 5). But it was influenced by considerable heterogeneity caused by neo-ChRT, the use of DWI and the individual differences of radiologists and surgeons. So, RCT studies with larger samples are needed to establish the influence of different tesla.

The location of tumor is also an important factor that can influence the accuracy of MRI for the assessment of MRF. Studies found that MRI had lower accuracy to assess MRF in anterior tumors than in posterior tumors [25, $30,52]$. The anterior perirectal fat is usually very thin, which makes it more difficult to delimit the anterior MRF or Denonvilliers' fascia in MRI. Besides, it is less reliable to predict MRF in lower rectal tumor than in middle and upper rectal tumors by MRI because lower rectal tumor is much closer to the horizontal position and anteriorly closer to the seminal vesicles in male patients and to the posterior vaginal wall in female patients. Glimelius et al. [53] proposed that in low tumors that are below the levator muscles, where the MRF cannot be defined, the relationship to the sphincters should be described. In our meta-analysis, the proportions of tumors arising from different locations were varied among each article (table 1). Due to lack of data we did not perform a detailed analysis. This may be one limitation of our study. Recently, in order to enhance the accuracy of MRI in staging low rectal cancer, some studies proposed a novel MRI staging technique, which was based on the relationship of the tumor to the levators and individual components of the sphincter complex [53-55]. However, the benefit of the new staging technique is not clear and larger prospective studies are needed to confirm its benefit.

There are other factors affecting the accuracy of MRI for the assessment of MRF, such as the tumor stage and the histological type of tumor. Kim and colleagues [56] found $\mathrm{T} 3$ tumor was related to the incorrect prediction of MRF. Different types of tumor can also influence the accuracy. Studies showed mutinous tumors would increase the error for the assessment of MRF in neo-ChRT patients, because mutinous tumors had higher signal intensity after chemoradiation therapy than non-mutinous tumors, which made it difficult to differentiate residual tumor from inactive mucin pools $[38,40]$.

According to NCCN, the definition of MRF+ in histopathology includes both secondary to metastatic lymph node and direct tumor extension [10]. In the 14 included studies, only $6[23,26,28,30,32,33]$ gave a positive instruction on whether metastatic lymph node was used for measuring the closest distance to MRF (table 1). This may be another limitation of our study. We analyzed these 6 studies and found that they had a lower sensitivity and higher specificity when MRF is positive and when metastatic lymph node was present (table 5).

There are several other limitations in our study. First and also the most important one is the bias coursed by the quality of surgery. Quirke et al. [57] found that surgery was achieved in the mesorectal plane in only $52 \%$ patients (34\% in intramesorectal plane and $13 \%$ in muscularis propria plane), and the ratio was lower in abdominoperineal excision compared with anterior resection, but similar in primary surgery and surgery after neo-ChRT. Besides, Martling et al. [33] thought that the surgeon was aware of the findings on preoperative MRI, which may have influenced the surgical approach, thus leading to extended resection in patients with a predicted involved MRF. These non-standard TME surgeries with extended or contracted resection reduce the accuracy of MRI. Second, we restricted our search to the studies published in English, which may lead to language bias. Third, 3 studies [35-37] that could not be used to extract or reconstruct $2 \times 2$ contingency tables were excluded. The exclusion of these data may influence our results. Fourth, in our study, the time interval between second MRI and surgery was different (table 2), and as we know, changes in disease status can occur in this time frame [58]. However, van der Paardt et al. [59] described a group with a maximum 6-week interval between second MRI and surgery, and found that they had a difference but which was not statistically significant. So in our opinion, the different time intervals were another source of bias, but during a certain time frame. How to clearly define this interval and its relationship with the results needs further investigation. Fifth, considerable heterogeneity was observed in this meta-analysis and did not appear to diminish when the 2 studies with lowest and highest accuracy were excluded. The heterogeneity was probably caused by variations in study design, patient characteristics, different MRI parameters, and the individual differences of radiologists, surgeons and pathologists.

In conclusion, MRI has a favorable specificity in the assessment of preoperative MRF for rectal cancer, but its sensitivity remains to be further investigated. Our metaanalysis found that the definition of $\leq 1 \mathrm{~mm}$ is the most appropriate in MRI, and neo-ChRT has marked influence on the effectiveness of MRI in assessing MRF. 


\section{Acknowledgement}

The authors thank Siyan Zhan, MD, PhD, for her assistance with the statistical analysis, and Jundong Zhang, MD, and Lihuan Ren, MD, for editorial assistance.

\section{Disclosure Statement}

The authors have no conflicts of interest to disclose.

\section{Appendix 1}

Search strategies

\begin{tabular}{|c|c|c|c|}
\hline Database & Sear & ch strategies & Papers, $\mathrm{n}$ \\
\hline PubMed & $\begin{array}{l}\# 1 \\
\# 2 \\
\# 3 \\
\# 4 \\
\# 5 \\
\# 6\end{array}$ & $\begin{array}{l}\text { rectal neoplasms [MeSH Terms] } \\
(((\text { cancer* [Text Word]) OR carcinoma* [Text Word] }) \text { OR neoplas* [Text Word] }) \text { OR } \\
\text { malignan* [Text Word] } \\
\text { rectal* } \\
\text { (\#2) AND \#3 } \\
\text { (\#1) OR \#4 } \\
\text { ((((((circumferential resection margin* [Text Word]) OR circumferential margin* [Text Word]) } \\
\text { OR mesorectal fascia* [Text Word]) OR resection margin* [Text Word]) OR radial resection } \\
\text { margin* [Text Word]) OR meso-rectal margin* [Text Word]) OR circumferential margin } \\
\text { involvement* [Text Word] } \\
\text { magnetic resonance imaging [MeSH Terms] } \\
(((\text { MRI [Text Word]) OR magnetic resonance imaging [Text Word]) OR magnetic resonance } \\
\text { [Text Word]) OR magnetic resonance imag* [Text Word] } \\
\text { (\#7) OR \#8 } \\
\text { (diagnosis [MeSH Terms]) OR sensitivity and specificity [MeSH Terms] } \\
((((((((((l i k e l i h o o d \text { functions [MeSH Terms]) OR likelihood ratio [Text Word]) OR likelihood } \\
\text { [Text Word]) OR sensitivity [Text Word]) OR specificity [Text Word]) OR accura* [Text } \\
\text { Word]) OR false positive rate [Text Word]) OR false negative rate [Text Word]) OR predicative } \\
\text { value [Text Word]) OR Youden's index [Text Word]) OR kappa statistic [Text Word]) OR } \\
\text { reliability [Text Word] } \\
\text { (\#11) OR \#10 } \\
\text { (((\#5) AND \#6) AND \#9) AND \#12 Filters: Publication date from 1999/01/01 to 2012/06/30; } \\
\text { Humans; English }\end{array}$ & 132 \\
\hline $\begin{array}{l}\text { The Cochrane } \\
\text { Central Register } \\
\text { of Controlled } \\
\text { Trials }\end{array}$ & $\begin{array}{l}\# 1 \\
\# 2 \\
\# 3 \\
\# 4 \\
\# 5 \\
\# 6 \\
\# 7 \\
\# 8 \\
\# 9 \\
\\
\# 10 \\
\# 11 \\
\# 12 \\
\# 13 \\
\# 14 \\
\# 15 \\
\# 16 \\
\# 17\end{array}$ & $\begin{array}{l}\text { (cancer*): ti,ab,kw or (carcinom*): ti,ab,kw or (neoplas*): ti,ab,kw or (malignan*): ti,ab,kw } \\
\text { MeSH descriptor Rectal Neoplasms explode all trees } \\
\text { (rectal*): ti,ab,kw } \\
\text { (\#1 AND \#3) } \\
\text { (\#4 OR \#2) } \\
\text { MeSH descriptor Magnetic Resonance Imaging explode all trees } \\
\text { (MRI): ti,ab,kw or (magnetic resonance imaging): ti,ab,kw } \\
\text { (\#6 OR \#7) } \\
\text { (circumferential resection margin*): ti,ab,kw or (circumferential margin*): ti,ab,kw or } \\
\text { (mesorectal fascia*): ti,ab,kw or (radial resection margin*): ti,ab,kw or (resection margin*): } \\
\text { ti,ab,kw or (circumferential margin involvement*): ti,ab,kw } \\
\text { (sensitivity): ti,ab,kw or (specificity): ti,ab,kw or (accura*): ti,ab,kw or (Youden's index): ti,ab,kw } \\
\text { or (kappa statistic): ti,ab,kw } \\
\text { (false positive rate): ti,ab,kw or (false negative rate): ti,ab,kw or (predicative value): ti,ab,kw or } \\
\text { (likelihood ratio): ti,ab,kw or (likelihood): ti,ab,kw } \\
\text { (\#10 OR \#11) } \\
\text { MeSH descriptor Likelihood Functions explode all trees } \\
\text { MeSH descriptor Diagnosis explode all trees } \\
\text { MeSH descriptor Sensitivity and Specificity explode all trees } \\
\text { (\#13 OR \#14 OR\#15 OR \#12) } \\
\text { (\#5 AND \#8 AND \#12 AND \#16), from } 1999 \text { to } 2012\end{array}$ & 8 \\
\hline
\end{tabular}


Appendix 1 (continued)

\begin{tabular}{|c|c|c|c|}
\hline $\begin{array}{l}\text { Database } \\
\text { Medline and } \\
\text { Embase }\end{array}$ & \multicolumn{2}{|c|}{ Search strategies } & Papers, $\mathrm{n}$ \\
\hline $\begin{array}{l}\text { Medline and } \\
\text { Embase }\end{array}$ & $\begin{array}{l}\# 1 \\
\# 2 \\
\# 3 \\
\# 4 \\
\# 5 \\
\# 6 \\
\# 7 \\
\# 8 \\
\# 9 \\
\# 10 \\
\# 11 \\
\# 12 \\
\# 13 \\
\# 14 \\
\# 15\end{array}$ & $\begin{array}{l}\text { 'rectal tumor'/exp } \\
\text { cancer* OR carcinom* OR neoplas* OR malignan* } \\
\text { rectal* } \\
\text { (\#2 AND \#3) } \\
\text { (\#1 OR \#4) } \\
\text { 'nuclear magnetic resonance imaging'/exp } \\
\text { 'mri'/exp OR 'magnetic resonance imaging'/exp } \\
\text { (\#6 OR \#7) } \\
\text { 'circumferential resection margin' OR 'resection margin' OR 'circumferential margin' OR } \\
\text { 'mesorectal fascia' OR 'radial resection margin' OR 'circumferential margin involvement' } \\
\text { 'diagnosis'/exp } \\
\text { 'sensitivity and specificity'/exp } \\
\text { sensitivity OR specificity OR 'false positive rate' OR 'false negative rate' OR 'predicative value' } \\
\text { OR 'Youden index'/exp OR 'likelihood ratio' OR 'likelihood function' OR 'kappa statistic'/exp } \\
\text { accura* } \\
\text { (\#10 OR \#11 OR \#12 OR \#13) } \\
\text { (\#5 AND \#8 AND \#9 AND \#14) AND ([controlled clinical trial]/lim OR [randomized controlled } \\
\text { trial]/lim) AND ([article]/lim OR [article in press]/lim OR [conference abstract]/lim OR } \\
\text { [conference paper]/lim OR [erratum]/lim OR [letter]/lim OR [note]/lim OR [short survey]/lim) } \\
\text { AND [English]/lim AND [humans]/lim AND [1-1-1999]/sd NOT [30-6-2012]/sd }\end{array}$ & 249 \\
\hline
\end{tabular}

\section{Appendix 2}

Sixteen studies which were excluded because of different definitions of MRF+

\begin{tabular}{|c|c|c|c|c|c|}
\hline Study & Year & Journal & Definition of MRF+ in MRI & $\begin{array}{l}\text { Definition of } \\
\text { MRF+ in } \\
\text { histopathology }\end{array}$ & $\begin{array}{l}2 \times 2 \\
\text { contingency } \\
\text { tables }\end{array}$ \\
\hline Akasu & 2009 & Ann Surg Oncol & unclear & unclear & yes \\
\hline Kim & 2009 & J Magn Reson Imaging & $\leq 2 \mathrm{~mm}$ & $\leq 2 \mathrm{~mm}$ & yes* \\
\hline Salerno & 2009 & Dis Colon Rectum & $\begin{array}{l}\text { tumor on MRI invading into the intersphincteric } \\
\text { plane or laying within } 1 \mathrm{~mm} \text { of levator muscle or } \\
\text { tumor invading into the external anal sphincter and } \\
\text { infiltrating or extending beyond the levators with or } \\
\text { without invading an adjacent organ }\end{array}$ & $\leq 1 \mathrm{~mm}$ & yes \\
\hline Youssef & 2009 & Colorectal Dis & unclear & $\leq 1 \mathrm{~mm}$ & no \\
\hline Kim & 2008 & Eur J Surg Oncol & $\leq 2 \mathrm{~mm}$ & $\leq 2 \mathrm{~mm}$ & no \\
\hline Vliegen & 2008 & Radiology & $\leq 2 \mathrm{~mm}$ & $\leq 2 \mathrm{~mm}$ & yes* \\
\hline Peschaud & 2005 & Dis Colon Rectum & $\leq 2 \mathrm{~mm}$ & $\leq 2 \mathrm{~mm}$ & yes \\
\hline Vliegen & 2005 & Radiology & $\begin{array}{l}\text { diffuse stranding from the tumor into the } \\
\text { mesorectal fascia, a nodular tumor mass } \\
\text { encroaching the mesorectal fascia, or a tumor } \\
\text { deposit or suspected lymph node in direct contact } \\
\text { with the mesorectal fascia }\end{array}$ & $\leq 1 \mathrm{~mm}$ & yes \\
\hline Branagan & 2004 & Dis Colon Rectum & $\begin{array}{l}\text { contiguity of tumor and the mesorectal fascial } \\
\text { reflection }\end{array}$ & unclear & yes \\
\hline
\end{tabular}




\begin{tabular}{lllll}
\hline Study & Year & Journal & Definition of MRF+ in MRI & $\begin{array}{l}\text { Definition of } \\
\text { MRF+ in } \\
\text { histopathology } \begin{array}{l}2 \times 2 \\
\text { contingency } \\
\text { tables }\end{array}\end{array}$ \\
\hline Mathur & 2003 & Colorectal Dis & $\begin{array}{l}\text { tumor was seen to involve or encroach upon the } \\
\text { mesorectal envelope }\end{array}$ & unclear \\
\hline Botterill & 2001 & Colorectal Dis & $\begin{array}{l}\text { tumor in broad contact with lateral edge of meso- } \\
\text { rectum coupled with signal change in surrounding } \\
\text { tissue }\end{array}$ & unclear \\
\hline
\end{tabular}

* Studies which had two reviewers to evaluate the value of MRI in the assessment of preoperative MRF for rectal cancer, and have two sets of data. In our meta-analysis, we separated the data as if they were from two different studies.

\section{References}

$>1$ Heald RJ, Husband EM, Ryall RD: The mesorectum in rectal cancer surgery - the clue to pelvic recurrence? Br J Surg 1982;69:613-616.

$\checkmark 2$ Heald RJ, Ryall RD: Recurrence and survival after total mesorectal excision for rectal cancer. Lancet 1986;1:1479-1482.

-3 McAnena OJ, Heald RJ, Lockhart-Mummery HE: Operative and functional results of total mesorectal excision with ultra-low anterior resection in the management of carcinoma of the lower one-third of the rectum. Surg Gynecol Obstet 1990;170:517-521.

4 MacFarlane JK, Ryall RD, Heald RJ: Mesorectal excision for rectal cancer. Lancet 1993;341: 457-460.

$\checkmark 5$ Enker WE, Thaler HT, Cranor ML, Polyak T: Total mesorectal excision in the operative treatment of carcinoma of the rectum. J Am Coll Surg 1995;184:335-346.

$\checkmark 6$ Wibe A, Møller B, Norstein J, Carlsen E, Wiig JN, Heald RJ, Langmark F, Myrvold F, Søreide O; Norwegian Rectal Cancer Group: A national strategic change in treatment policy for rectal cancer - implementation of total mesorectal excision as routine treatment in Norway. A national audit. Dis Colon Rectum 2002;45:857-866.

$>7$ Adam IJ, Mohamdee MO, Martin IG, Scott N, Finan PJ, Johnston D, Dixon MF, Quirke P: Role of circumferential margin involvement in the local recurrence of rectal cancer. Lancet 1994;344:707-711.

8 Eriksen MT, Wibe A, Haffner J, Wiig JN; Norwegian Rectal Cancer Group: Prognostic groups in 1,676 patients with $\mathrm{T} 3$ rectal cancer treated without preoperative radiotherapy. Dis Colon Rectum 2007;50:156-167.
-9 Vliegen RF, Beets GL, Lammering G, Dresen RC, Rutten HJ, Kessels AG, Oei TK, de Bruïne AP, van Engelshoven JM, Beets-Tan RG: Mesorectal fascia invasion after neoadjuvant chemotherapy and radiation therapy for locally advanced rectal cancer: accuracy of MR imaging for prediction. Radiology 2008;246:454462.

10 Benson AB, Bekaii-Saab T, Chan E, Chen YJ, Choti MA, Cooper HS, Engstrom PF, Enzinger PC, Fakih MG, Fuchs CS, Grem JL, Hunt S, Leong LA, Lin E, Martin MG, May KS, Mulcahy MF, Murphy K, Rohren E, Ryan DP, Saltz L, Sharma S, Shibata D, Skibber JM, Small W Jr, Sofocleous CT, Venook AP, Willett CG, Freedman-Cass DA, Gregory KM: Rectal cancer. J Natl Compr Canc Netw 2012; 10: 15281564

11 Nagtegaal ID, Quirke P: What is the role for the circumferential margin in the modern treatment of rectal cancer. J Clin Oncol 2008; 26:303-312.

12 Wolberink SV, Beets-Tan RG, de Haas-Kock DF, Span MM, van de Jagt EJ, van de Velde CJ, Wiggers T: Conventional CT for the prediction of an involved circumferential resection margin in primary rectal cancer. Dig Dis 2007;25:80-85.

13 Maizlin ZV, Brown JA, So G, Brown C, Phang TP, Walker ML, Kirby JM, Vora P, Tiwari P: Can CT replace MRI in preoperative assessment of the circumferential resection margin in rectal cancer. Dis Colon Rectum 2010;53: 308-314.

14 Lahaye MJ, Engelen SME, Nelemans PJ, Beets GL, van de Velde CJ, van Engelshoven JM, Beets-Tan RG: Imaging for predicting the risk factors, the circumferential resection margin and nodal disease, of local recurrence in rectal cancer: a meta-analysis. Semin Ultrasound CT MR 2005;26:259-268.
15 Purkayastha S, Tekkis PP, Athanasiou T, Tilney HS, Darzi AW, Heriot AG: Diagnostic precision of magnetic resonance imaging for preoperative prediction of the circumferential margin involvement in patients with rectal cancer. Colorect Dis 2007;9:402-411.

16 Al-Sukhni E, Milot L, Fruitman M, Beyene J, Victor JC, Schmocker S, Brown G, McLeod R, Kennedy E: Diagnostic accuracy of MRI for assessment of T category, lymph node metastases, and circumferential resection margin involvement in patients with rectal cancer: a systematic review and meta-analysis. Ann Surg Oncol 2012;19:2212-2223.

17 Reitsma JB, Rutjes AWS, Whiting P, Vlassov VV, Leeflang MMG, Deeks JJ: Chapter 9: Assessing methodological quality. Cochrane Handbook for Systematic Reviews of Diagnostic Test Accuracy Version 1.0.0. The Cochrane Collaboration, 2009.

18 Whiting P, Harbord R, Kleijnen J: No role for quality scores in systematic reviews of diagnostic accuracy studies. BMC Med Res Methodol 2005;26:9.

19 Leeflang MM, Deeks JJ, Gatsonis C, Bossuyt PM; Cochrane Diagnostic Test Accuracy Working Group: Systematic reviews of diagnostic test accuracy. Ann Intern Med 2008; 149:889-897.

20 Reitsma JB, Glas AS, Rutjes AW, Scholten RJ, Bossuyt PM, Zwinderman AH: Bivariate analysis of sensitivity and specificity produces informative summary measures in diagnostic reviews. J Clin Epidemiol 2005;58:982-990.

21 Giusti S, Buccianti P, Castagna M, Fruzzetti E, Fattori S, Castelluccio E, Caramella D, Bartolozzi C: Preoperative rectal cancer staging with phased-array MR. Radiat Oncol 2012;7: 29. 
$\longrightarrow 22$ Nougaret S, Rouanet P, Molinari N, Pierredon MA, Bibeau F, Azria D, Lemanski C, Assenat E, Duffour J, Ychou M, Reinhold C, Gallix B: MR volumetric measurement of low rectal cancer helps predict tumor response and outcome after combined chemotherapy and radiation therapy. Radiology 2012;263:409-418.

23 Pomerri F, Pucciarelli S, Maretto I, Zandonà M, Del Bianco P, Amadio L, Rugge M, Nitti D, Muzzio PC: Prospective assessment of imaging after preoperative chemoradiotherapy for rectal cancer. Surgery 2011;149:56-64.

24 Taylor FG, Quirke P, Heald RJ, Moran B, Blomqvist L, Swift I, St Rose S, Sebag-Montefiore DJ, Tekkis P, Brown G; MERCURY Study Group: One millimetre is the safe cutoff for magnetic resonance imaging prediction of surgical margin status in rectal cancer. Br J Surg 2011;98:872-879.

25 Kim YW, Cha SW, Pyo J, Kim NK, Min BS, Kim MJ, Kim H: Factors related to preoperative assessment of the circumferential resection margin and the extent of mesorectal invasion by magnetic resonance imaging in rectal cancer. World J Surg 2009;33:1952-1960.

26 Tytherleigh MG, Ng VV, Pittathankal AA, Wilson MJ, Farouk R: Preoperative staging of rectal cancer by magnetic resonance imaging remains an imperfect tool. ANZ J Surg 2008; 78:194-198.

-27 Kulkarni T, Gollins S, Maw A, Hobson P, Byrne R, Widdowson D: Magnetic resonance imaging in rectal cancer downstaged using neoadjuvant chemoradiation: accuracy of prediction of tumour stage and circumferential resection margin status. Colorectal Dis 2008; 10:479-489.

-28 Strassburg J, Lewin A, Ludwig K, Kilian L, Linke J, Loy V, Knuth P, Püttcher O, Ruehl U, Stöckmann F, Hackenthal M, Hopfenmüller W, Huppertz A: Optimised surgery (so-called TME surgery) and high-resolution MRI in the planning of treatment of rectal carcinoma. Langenbecks Arch Surg 2007;392:179-188.

29 Videhult P, Smedh K, Lundin P, Kraaz W: Magnetic resonance imaging for preoperative staging of rectal cancer in clinical practice: high accuracy in predicting circumferential margin with clinical benefit. Colorectal Dis 2007;9:412-419.

-30 MERCURY Study Group: Diagnostic accuracy of preoperative magnetic resonance imaging in predicting curative resection of rectal cancer: prospective observational study. BMJ 2006;333:779-782.

-31 Ferri M, Laghi A, Mingazzini P, Iafrate F, Meli L, Ricci F, Passariello R, Ziparo V: Pre-operative assessment of extramural invasion and sphincteral involvement in rectal cancer by magnetic resonance imaging with phased-array coil. Colorectal Dis 2005;7:387-393.

- 32 Brown G, Radcliffe AG, Newcombe RG, Dallimore NS, Bourne MW, Williams GT: Preoperative assessment of prognostic factors in rectal cancer using high-resolution magnetic resonance imaging. Br J Surg 2003;90:355364.
33 Martling A, Holm T, Bremmer S, Lindholm J, Cedermark B, Blomqvist L: Prognostic value of preoperative magnetic resonance imaging of the pelvis in rectal cancer. Br J Surg 2003; 90:1422-1428.

-34 Blomqvist L, Rubio C, Holm T, Machado M, Hindmarsh T: Rectal adenocarcinoma: assessment of tumour involvement of the lateral resection margin by MRI of resected specimen. Br J Radiol 1999;72:18-23.

35 Burton S, Brown G, Daniels IR, Norman AR, Mason B, Cunningham D; Royal Marsden Hospital, Colorectal Cancer Network: MRI directed multidisciplinary team preoperative treatment strategy: the way to eliminate positive circumferential margins? Br J Cancer 2006;94:351-357.

- 36 Salerno G, Daniels IR, Brown G, Norman AR, Moran BJ, Heald RJ: Variations in pelvic dimensions do not predict the risk of circumferential resection margin involvement in rectal cancer. World J Surg 2007;31:1313-1320.

- 37 Adeyemo D, Hutchinson R: Preoperative staging of rectal cancer: pelvic MRI plus abdomen and pelvic CT. Does extrahepatic abdomen imaging matter? A case for routine thoracic CT. Colorectal Dis 2009;11:259-263.

38 Kim SH, Lee JM, Park HS, Eun HW, Han JK, Choi BI: Accuracy of MRI for predicting the circumferential resection margin, mesorectal fascia invasion, and tumor response to neoadjuvant chemoradiotherapy for locally advanced rectal cancer. J Magn Reson Imaging 2009;29:1093-1101.

- 39 Brown G, Richards CJ, Newcombe RG, Dallimore NS, Radcliffe AG, Carey DP, Bourne MW, Williams GT: Rectal carcinoma-thin section MR imaging for staging in 28 patients. Radiology 1999;211:215-222.

40 Allen SD, Padhani AR, Dzik-Jurasz AS, Glynne-Jones R: Rectal carcinoma: MRI with histologic correlation before and after chemoradiation therapy. AJR Am J Roentgenol 2007; 188:442-451.

41 Beets-Tan RG, Beets GL, Vliegen RF, Kessels AG, Van Boven H, De Bruine A, von Meyenfeldt MF, Baeten CG, van Engelshoven JM: Accuracy of magnetic resonance imaging in prediction of tumour-free resection margin in rectal cancer surgery. Lancet 2001;357:497504.

42 Engelen SM, Maas M, Lahaye MJ, Leijtens JW, van Berlo CL, Jansen RL, Breukink SO, Dejong CH, van de Velde CJ, Beets-Tan RG, Beets GL: Modern multidisciplinary treatment of rectal cancer based on staging with magnetic resonance imaging leads to excellent local control, but distant control remains a challenge. Eur J Cancer 2013;49:2311-2320.

Value of MRI Assessment MRF in Rectal Cancer
43 Bujko K, Nowacki MP, Nasierowska-Guttmejer A, Michalski W, Bebenek M, Pudełko M, Kryj M, Oledzki J, Szmeja J, Słuszniak J, Serkies K, Kładny J, Pamucka M, Kukołowicz $\mathrm{P}$ : Sphincter preservation following preoperative radiotherapy for rectal cancer: report of a randomised trial comparing short-term radiotherapy versus conventionally fractionated radiochemotherapy. Radiother Oncol 2004;72:15-24.

44 Bosset JF, Calais G, Mineur L, Maingon P, Radosevic-Jelic L, Daban A, Bardet E, Beny A, Briffaux A, Collette L: Enhanced tumorocidal effect of chemotherapy with preoperative radiotherapy for rectal cancer: preliminary results - EORTC 22921. J Clin Oncol 2005;23: 5620-5627.

45 Genovesi D, Filippone A, Ausili Cèfaro G, Trignani M, Vinciguerra A, Augurio A, Di Tommaso M, Borzillo V, Sabatino F, Innocenti P, Liberatore E, Colecchia G, Tartaro A, Cotroneo AR: Diffusion-weighted magnetic resonance for prediction of response after neoadjuvant chemoradiation therapy for locally advanced rectal cancer: preliminary results of a monoinstitutional prospective study. Eur J Surg Oncol 2013;39:1071-1078.

46 Park MJ, Kim SH, Lee SJ, Jang KM, Rhim H: Locally advanced rectal cancer: added value of diffusion-weighted MR imaging for predicting tumor clearance of the mesorectal fascia after neoadjuvant chemotherapy and radiation therapy. Radiology 2011;260:771-780.

47 Lambregts DM, Vandecaveye V, Barbaro B, Bakers FC, Lambrecht M, Maas M, Haustermans K, Valentini V, Beets GL, Beets-Tan RG: Diffusion-weighted MRI for selection of complete responders after chemoradiation for locally advanced rectal cancer: a multicenter study. Ann Surg Oncol 2011;18:2224-2231.

48 Kim SH, Lee JY, Lee JM, Han JK, Choi BI: Apparent diffusion coefficient for evaluating tumour response to neoadjuvant chemoradiation therapy for locally advanced rectal cancer. Eur Radiol 2011;21:987-995.

49 Koh DM, Collins DJ: Diffusion-weighted MRI in the body: applications and challenges in oncology. AJR Am J Roentgenol 2007;188: 1622-1635.

50 Roth Y, Tichler T, Kostenich G, Ruiz-Cabello J, Maier SE, Cohen JS, Orenstein A, Mardor Y: High-b-value diffusion-weighted MR imaging for pretreatment prediction and early monitoring of tumor response to therapy in mice. Radiology 2004;232:685-692.

51 Peschaud F, Cuenod CA, Benoist S, Julié C, Beauchet A, Siauve N, Taieb-Kasbi F, Penna C, Nordlinger B: Accuracy of magnetic resonance imaging in rectal cancer depends on location of the tumor. Dis Colon Rectum 2005; 48:1603-1609.

52 Maas M, Lambregts DM, Lahaye MJ, Beets GL, Backes W, Vliegen RF, Osinga-de Jong M, Wildberger JE, Beets-Tan RG: T-staging of rectal cancer: accuracy of 3.0 tesla MRI compared with 1.5 tesla. Abdom Imaging 2012;37: 475-481. 
53 Glimelius B, Beets-Tan R, Blomqvist L, Brown G, Nagtegaal I, Påhlman L, Quirke P, Valentini V, van de Velde C: Mesorectal fascia instead of circumferential resection margin in preoperative staging of rectal cancer. J Clin Oncol 2011;29:2142-2143.

-54 Salerno GV, Daniels IR, Moran BJ, Heald RJ, Thomas K, Brown G: Magnetic resonance imaging prediction of an involved surgical resection margin in low rectal cancer. Dis Colon Rectum 2009;52:632-639.

55 Shihab OC, How P, West N, George C, Patel U, Quirke P, Heald RJ, Moran BJ, Brown G: Can a novel MRI staging system for low rectal cancer aid surgical planning? Dis Colon Rectum 2011;54:1260-1264.
56 Baik SH, Kim NK, Lee KY, Sohn SK, Cho CH, Kim MJ, Kim H, Shinn RK: Factors influencing pathologic results after total mesorectal excision for rectal cancer: analysis of consecutive 100 cases. Ann Surg Oncol 2008;15:721-728.

57 Quirke P, Steele R, Monson J, Grieve R, Khanna S, Couture J, O'Callaghan C, Myint AS, Bessell E, Thompson LC, Parmar M, Stephens RJ, Sebag-Montefiore D; MRC CR07/NCICCTG CO16 Trial Investigators; NCRI Colorectal Cancer Study Group: Effect of the plane of surgery achieved on local recurrence in patients with operable rectal cancer: a prospective study using data from the MRC CR07 and NCIC-CTG CO16 randomised clinical trial. Lancet 2009;373:821-828.
58 Habr-Gama A, Perez RO, Nadalin W, Sabbaga J, Ribeiro U Jr, Silva e Sousa AH Jr, Campos FG, Kiss DR, Gama-Rodrigues J: Operative versus nonoperative treatment for stage 0 distal rectal cancer following chemoradiation therapy: long-term results. Ann Surg 2004; 240:711-717.

59 van der Paardt MP, Zagers MB, Beets-Tan RG, Stoker J, Bipat S: Patients who undergo preoperative chemoradiotherapy for locally advanced rectal cancer restaged by using diagnostic MR imaging: a systematic review and meta-analysis. Radiology 2013;269:101112. 